\title{
CARACTERIZAÇÃO DOS ÁCIDOS HÚMICOS EXTRAÍDOS DE UM LATOSSOLO VERMELHO-AMARELO E DE UM PODZOL POR ANÁLISE TERMODIFERENCIAL E PELA ESPECTROSCOPIA DE ABSORÇÃO NO INFRAVERMELHO(1)
}

\author{
V.M. BENITES (2), E.S. MENDONÇA ${ }^{(3)}$, \\ C. E. R. SCHAEFER ${ }^{(3)} \&$ L. MARTIN NETO(4)
}

\begin{abstract}
RESUMO
A caracterização espectroscópica de substâncias húmicas do solo tem-se desenvolvido aceleradamente durante as últimas décadas. Entretanto, poucos são os trabalhos que associam esta técnica a estudos pedológicos envolvendo diferentes classes de solo, sobretudo em condições tropicais. Os ácidos húmicos extraídos de amostras de diferentes horizontes de um Latossolo VermelhoAmarelo e de um Podzol, ambos situados na Serra do Brigadeiro, Araponga (MG), foram caracterizados, por meio da espectroscopia de absorção no infravermel ho com transformada de Fourier (FTIR) e por análise termodiferencial. Os espectros de infravermel ho indicaram diferenças qualitativas entre os ácidos húmicos extraídos dos diferentes solos e entre os ácidos húmicos extraídos de diferentes horizontes de um mesmo solo. Observou-se a redução de intensidade dos picos relativos a estruturas alifáticas com o aprofundamento nos perfis, sendo evidentes os picos relativos a pol issacarídeos nos horizontes orgâni cos. I mpurezas minerais foram observadas em todos os espectros de ácido húmico não purificado, indicando a necessidade do processo de purificação. 0 tratamento com $\mathrm{HF}-\mathrm{HCl}$ demonstrou-se eficiente na remoção dessas impurezas, tendo os espectros diferenciais de ácidos húmicos antes e depois do processo de purificação apresentado o padrão típico de minerais secundários como caulinita e gi bbsita. Após a purificação, observou-se um aumento na intensidade dos picos referentes aos grupos carboxílicos, evidenciando sua participação nas ligações entre os ácidos húmicos e a matriz mineral. A análise termodiferencial indicou maior resistência à termodegradação dos ácidos húmicos extraídos do horizonte $\mathrm{Bhs}$ do Podzol, em relação ao ácido húmico extraído do horizonte $\mathrm{A}$ do Latossolo, $\mathrm{O}$ que concorda com a feição mais aromática do primeiro, revelada pela análise dos espectros de infravermelho.
\end{abstract}

Termos de indexação: matéria orgânica do solo, pedologia, Serra do Brigadeiro.

\footnotetext{
(1) Recebido para publicação em março de 1998 e aprovado em abril de 1999.

(2) Doutorando em Sol os e Nutrição de Plantas, Universidade Federal de Viçosa - UFV. Av. PH Rolfs, s/n, CEP 36571-000 Viçosa (MG). E-mail:vinicius@solos.ufv.br.

(3) Professor Adjunto do Departamento de Solos, UFV.

(4) Pesquisador da E mbrapa Instrumentação Agropecuária. Rua XV de novembro, 1452, CEP 13560-970 São Carlos (SP).
} 


\title{
SUMMARY: HUMIC ACID CHARACTERIZATION OF A PODZOL AND A RED YELLOW LATOSOL BY FTIR SPECTROSCOPY AND TD ANALYSIS
}

\begin{abstract}
The spectroscopic characterization of humi c substances in soil has been widely used. However, few studies have been carried out concerning the pedology of tropical soi ls using such technique. Humicacids (HA) extracted from contrasting horizons of a Red Yellow Latosol and a Podzol, on the highlands of the Serra do Brigadeiro, Araponga, Minas Gerais, were characterized by means of Fourier Transformed I nfrared Absorption Spectroscopy (FTIR) and TD analysis. The spectra indicated qualitative differences between the HA extracted from differing soils, and also betwen HA extracted from different horizons in a given soil. Thepeaks associated with ali phatic structures showed decreasing intensity with soil depth, and therewereevident pol issacariderelated peaks in theorganichorizons. Mineral impurities could be detected in all HA spectra of non-purified samples. The HF-HCl treatment was efficient in removing of thesemineral impurities, with thedifferential spectra betwen purified and non-purified HA revealing thepresence of caoliniteand gibbsite After theHA purification, an increasein intensity for the peaks of carboxyl groups was observed, suggesting therole of such groups in the process of mineral-HA interaction. The TD analysis indicated a greater resistance to thermodegradation of the humic acid extracted from Podzol horizon Bhs, as compared to the humic acid extracted from Latosol horizon A. This agrees with the more aromatic fashion of theformer, shown in theinfrared spectrum analysis.
\end{abstract}

Index terms: soil organi c matter, pedogenesis, Serra do Brigadei ro.

\section{INTRODUÇÃO}

A espectroscopia na faixa do infravermel ho permite identificar diferentes ligações químicas entre átomos pelas deformações rotacionais e vibracionais, as quais absorvem energia em determinada freqüência de ressonância, de acordo com as características químicas dos átomos envolvidos. A aplicação dessa técnica no estudo de substâncias húmicas permite observar a natureza, a reatividade e o arranjo estrutural de grupos funcionais que contêm oxigênio, a ocorrência de proteínas e carboidratos e o grau de pureza da amostra quanto a contaminantes inorgânicos, como argilas, metais e sais (Stevenson, 1982). E mbora existam diferenças entre os espectros obtidos de ácidos húmicos provenientes de diferentes ambientes, a feição geral dos espectros é bastante similar (MacCarthy \& Rice, 1985), ocorrendo variações nas proporções entre os sinais e pequenos desl ocamentos na freqüência de absorção.

Embora existam técnicas de avaliação semiquantitativa de grupos funcionais por espectroscopia no infravermel ho (Baes \& Bloom, 1989), os espectros, em geral, fornecem informações essencial mente qualitativas. A informação provida pela análise comparativa entre espectros éde maior valia que $a$ análise de um espectro isoladamente. $A$ presença de impurezas, por exemplo, pode ser observada pela análise do espectro antes e depois do processo de purificação e desmineralização dos ácidos húmi cos (Piccolo, 1988).
Com o desenvolvimento de novas técnicas, como a transformada de Fourier (FTIR), obteve-se maior velocidadena leitura dos espectros de infravermel ho, permitindo a obtenção de um somatório de muitos espectros, melhorando a definição dos sinais e a exatidão da análise. Paralelamente, com o desenvolvimento da técnica, observou-sea reduçãono custo do equi pamento e, atual mente, a espectroscopia no infravermel ho tornou-se relativamente simples e barata, quando comparada a outros métodos espectroscópicos, e ainda capaz de oferecer informações importantes para a anál ise qual itativa de ácidos húmicos, além de permitir a análise de amostras pequenas (ex.: $2 \mathrm{mg}$ ).

Outras ferramentas utilizadas na caracterização de substâncias húmicas são a análise termogravimétrica ea análise termodiferencial. Tais técnicas permitem estimar a aromaticidade de ácidos húmicos, pela análise de seu espectro de pirólise, observando a posição dos picos de perda de massa ou dos picos de reações exotérmicas, respectivamente (Stevenson, 1982). Segundo Schnitzer (1972), o processo de pirólise de ácidos húmicos ocorre em etapas, sendo primeiro degradadas as estruturas alifáticas, bem como os grupos funcionais, em temperaturas entre 250 e $280^{\circ} \mathrm{C}$, e, por último, degradadas as estruturas aromáticas, queconstituem o núcleo da macromolécula, em temperaturas superiores a $400^{\circ} \mathrm{C}$.

Neste trabalho, procurou-se caracterizar, pela espectroscopia no infravermel ho e por análise termodiferencial, ácidos húmicos extraídos desses 
diferentes pedoambientes e, ainda, avaliar o efeito do processo de purificação e desmineralização dos ácidos húmi cos sobre os espectros de infravermelho.

\section{MATE RIAL E MÉTODOS}

\section{Caracterização dos solos}

Foram utilizados um perfil de Latossolo Vermel ho-Amarelo e um perfil de Podzol, ambos coletados no Parque Estadual da Serra do Brigadeiro, Araponga (MG), sendo o primeiro coberto por mata atlântica eo segundo por campo dealtitude. Os solos foram estratificados em seus horizontes genéticos, sendo selecionados os horizontes $A+E$, Bhs eC do Podzol eos horizontes A e Bw do Latossolo (Quadro 1). Ambos os solos apresentaram, pela difração de raios-X, mineral ogia da argila constituída de caulinita, gibbsita e, em menores proporções, goethita, tendo a argila do Podzol apresentado mais gibbsita que a do Latossolo. Além dos horizontes minerais, foram amostrados os materiais orgânicos semidecompostos que se encontravam entre a serrapilheira fresca e o solo mineral, aqui denominados horizontes $O$. As amostras de solo foram secas ao ar e passadas em peneiras de $2 \mathrm{~mm}$. As amostras de material vegetal foram moídas até passarem em peneiras de 40 meshs.

\section{Extração e purificação dos ácidos húmicos}

Adicionaram-sea 20 g de cada amostra (10 g para os horizontes orgânicos) $200 \mathrm{~mL}$ desolução de $\mathrm{NaOH}$ 0,1 mol L-1, sob atmosfera de $N_{2}$. Após agitação horizontal branda por $24 \mathrm{~h}$, o material foi centrifugado a $10.000 \mathrm{~g}\left(\mathrm{FCR}_{\text {média }}\right)$, por $20 \mathrm{~min}$, à temperatura de $10^{\circ} \mathrm{C}$. O sobrenadante foi recol hido e, imediatamente, o $\mathrm{pH}$ foi reduzido para 2,0, por gotejamento de solução aquosa de $\mathrm{HCl} 20 \%$. O resíduo foi novamente submetido à extração, da mesma forma, e o sobrenadante juntado ao anterior novamente, reduzindo-se o pH para 2,0. O extrato acidificado foi reservado para a floculação dos ácidos húmicos. Após 18 h, o excesso de sobrenadante (fração ácido fúlvico) foi aspirado por sifonamento e descartado. O restante do material foi centrifugado a $5.000 \mathrm{~g}\left(\mathrm{FCR}_{\text {média }}\right)$, por $10 \mathrm{~min}$, eliminando-se o sobrenadante. O ácido húmico foi ressolubilizado em $200 \mathrm{~mL}$ de solução de $\mathrm{NaOH} 0,1 \mathrm{~mol} \mathrm{L-1}$, sob atmosfera de $\mathrm{N}_{2}$, e o processo repetido duas vezes. Esse passo permitiu a el iminação parcial deargilas. $\mathrm{O}$ ácido húmico floculado foi lavado duas vezes com solução $\mathrm{HCl}$ 0,01 mol L-1, dialisado em água deionizada por cinco dias, trocando-se a água diariamente, eliofilizado.

Alíquotas dos ácidos húmicos extraídos das amostras 3-Bhs e 12-A foram retiradas antes da diálise, imersas em solução de $\mathrm{HF}+\mathrm{HCl} 0,5 \%$ (Schnitzer, 1982), por $24 \mathrm{~h}$, à temperatura ambiente, e centrifugadas a $5.000 \mathrm{~g}$ ( $\left.F C R_{\text {média }}\right)$, repetindo-se o processo até que o sobrenadante se apresentasse translúcido, o que ocorreu no quarto ciclo, para ambas as amostras. Os ácidos húmicos purificados foram lavados duas vezes com solução $\mathrm{HCl}$ $0,01 \mathrm{~mol} \mathrm{~L}^{-1}$, dialisados eliofilizados.

\section{Análise termogravimétrica e termodiferencial}

O teor de cinzas foi obtido por análise termogravimétrica nos ácidos húmicos, extraídos das amostras 12-A e 3-Bhs, purificados enão purificados. Foram também obtidos os espectros termodiferenciais das mesmas amostras purificadas. Para ambas as análises, utilizou-se um aparelho de DTA-TG da marca Rigaku, com uma veloci dade de aquecimento de $2^{\circ} \mathrm{C}$ min-1, atéà temperatura de $650^{\circ} \mathrm{C}$, utilizandose 10,00 $\pm 0,01 \mathrm{mg}$ de AH li ofilizado.

\section{Análises espectroscópicas}

Os espectros noinfravermel ho dos ácidos húmicos purificados e não purificados foram lidos na faixa de 4.000-400 $\mathrm{cm}^{-1}$, em pastilhas de $\mathrm{KBr}(2 \mathrm{mg}$ de ácido húmico +200 mg de $\mathrm{KBr}$ seco), utilizando um espectrômetro de infravermel ho com transformada de Fourier, FTIR Spectrum 1000, fabricado pela

Quadro 1. Características ${ }^{(1)}$ texturais e químicas dos horizontes minerais de um Podzol e um Latossolo Vermelho-Amarelo da Serra do Brigadeiro, Araponga (MG)

\begin{tabular}{|c|c|c|c|c|c|c|c|c|c|c|c|c|c|}
\hline Perfil & Classe & Horizonte & Profundidade & Areia & Silte & Argila & $\mathbf{p H}$ & C & $\mathbf{N}$ & $C: N$ & СTC & $\mathbf{v}$ & m \\
\hline no & & & $\mathrm{cm}$ & 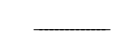 & $\mathrm{g} \mathrm{kg}^{-1}$ & ـ & & $-\mathrm{gk}$ & ${ }^{-1}$ & & $\mathrm{mmol}_{\mathrm{c}} \mathrm{kg}^{-1}$ & & - \\
\hline 3 & Podzol & $\begin{array}{l}A+E \\
\text { Bhs } \\
C\end{array}$ & $\begin{array}{r}0-14 \\
20-40 \\
48-62\end{array}$ & $\begin{array}{l}790 \\
830 \\
690\end{array}$ & $\begin{array}{r}100 \\
50 \\
140\end{array}$ & $\begin{array}{l}110 \\
120 \\
180\end{array}$ & $\begin{array}{l}4,1 \\
4,5 \\
4,8\end{array}$ & $\begin{array}{r}47,6 \\
27,0 \\
7,6\end{array}$ & $\begin{array}{l}2,4 \\
1,1 \\
0,4\end{array}$ & $\begin{array}{l}20 \\
25 \\
19\end{array}$ & $\begin{array}{r}19,9 \\
17,6 \\
9,3\end{array}$ & $\begin{array}{l}2 \\
1 \\
1\end{array}$ & $\begin{array}{l}88 \\
94 \\
93\end{array}$ \\
\hline 12 & Latossolo & $\begin{array}{l}A \\
B w\end{array}$ & $\begin{array}{c}0-10 \\
45-120\end{array}$ & $\begin{array}{l}420 \\
330\end{array}$ & $\begin{array}{l}150 \\
150\end{array}$ & $\begin{array}{l}430 \\
520\end{array}$ & $\begin{array}{l}4,0 \\
4,4\end{array}$ & $\begin{array}{l}46,8 \\
11,4\end{array}$ & $\begin{array}{l}4,1 \\
1,0\end{array}$ & $\begin{array}{l}11 \\
11\end{array}$ & $\begin{array}{r}21,5 \\
7,6\end{array}$ & $\begin{array}{l}4 \\
1\end{array}$ & $\begin{array}{l}83 \\
89\end{array}$ \\
\hline
\end{tabular}

\footnotetext{
(1) Segundo Benites (1998).
} 
Perkin-EImer, pertencente ao Centro Nacional de Pesquisa e Desenvolvimento de I nstrumentação Agropecuária da E MBRAPA, São Carlos (SP). Cada espectro foi obtido pela média de 128 leituras, com uma resolução de $4 \mathrm{~cm}^{-1}$. As leituras foram feitas em absorvância versus número de onda $\left(\mathrm{em}^{\mathrm{cm}} \mathrm{cm}^{-1}\right)$.

Para os cál cul os com espectros de infravermel ho e da análise termodiferencial, foi utilizado o programa Microcal Origin 3.5 (1994).

\section{RESULTADOSE DISCUSSÃO}

Os espectros no infravermelho, obtidos para os ácidos húmicos, demonstraram feições muito similares, com picos característicos em determinadas regiões, variando em intensidade, mas com poucas variações nas freqüências deabsorvância (Quadro 2). Os picos referentes às impurezas minerais foram vistos em todos os espectros de ácidos húmicos não purificados, ocorrendo maior intensidade destes nos horizontes minerais, sobretudo nos horizontes mais argilosos, 12-A e 12-Bw 2 (Figura 1) e 3-C (Figura 2).
A purificação dos ácidos húmicos com uma mistura de ácido fluorídrico e clorídrico $(\mathrm{HF}+\mathrm{HCl})$ causou redução significativa na intensidade dos picos de origem mineral e aumento de picos relativos a grupos orgânicos (Figuras 3 e 4). A diferença entre os espectros antes e depois da purificação demonstrou a redução de picos nas faixas de 3.750-3.400 e 1.100$450 \mathrm{~cm}^{-1}$, regiões típicas de sinais, causada por deformações axiais eangulares, respectivamente, de ligações $\mathrm{O}-\mathrm{H}$ e ligações $\mathrm{Si}-\mathrm{O}$, em minerais secundários (Russel, 1987). O espectro de ácido húmico não purificado extraído do horizonte $\mathrm{C}$ do Podzol (Figura 2) apresentou picos em 3.620, 3.527, 3.464 e $3.392 \mathrm{~cm}^{-1}$, considerados picos diagnósticos da gibbsita (Russel, 1987).

A diferença entre os espectros antes e depois da purificação dos ácidos húmicos extraídos do horizonte A de um Latossolo (amostra 12-A) (Figura 3) apresentou o padrão típico da caulinita (Russel, 1987), com picos muito bem definidos em 3.692, 3.656, 3.620, $1.100,1.034,1.008$ e $912 \mathrm{~cm}^{-1}$ (Figura 5). Esses dados demonstraram a eficiência do tratamento com $\mathrm{HF}+\mathrm{HCl}$ na desmineralização de ácidos húmicos, reforçados pela observação na

Quadro 2. Regiões de absorção no infravermelho observadas nas amostras de ácido húmico não purificadas, com respectivas descrições e referências bibliográficas

\begin{tabular}{|c|c|c|}
\hline Freqüência & Descrição & $\begin{array}{l}\text { Referência } \\
\text { bibliográfica }\end{array}$ \\
\hline \multicolumn{3}{|l|}{$\mathrm{cm}^{-1}$} \\
\hline 3.695 & Deformação axial de O-H em caulinita & Russel (1987) \\
\hline 3.620 & Deformação axial de O-H em caulinita e gibbsita & Russel (1987) \\
\hline $3.440-3.380$ & Deformação axial de O-H em grupo fenólico (Contribuição de OH alifático, $\mathrm{H}_{2} \mathrm{O}$ e amina) & $\begin{array}{l}\text { Baes \& Bloom (1989) } \\
\text { Stevenson (1982) }\end{array}$ \\
\hline 2.918 & Deformação axial assimétrica de C-H em metil e metileno & Baes \& Bloom (1989) \\
\hline 2.850 & Deformação axial simétrica de $\mathrm{C}-\mathrm{H}$ em metil e metileno & Baes \& Bloom (1989) \\
\hline $2.600-2.500$ & Deformação axial de O-H em grupo carboxílico & Baes \& Bloom (1989) \\
\hline $1.720-1.712$ & Deformação axial de $\mathrm{C}=\mathrm{O}$ em grupo carboxílico & Baes \& Bloom (1989) \\
\hline $1.660-1.620$ & $\begin{array}{l}\text { Deformação axial assimétrica do ânion carboxilato em ligação covalente com metal; } \\
\text { contribuição de amido, cetona ou quinona }\end{array}$ & $\begin{array}{l}\text { MacCarthy \& Rice (1985) } \\
\text { Vinkler et al. (1976) } \\
\text { Stevenson (1982) }\end{array}$ \\
\hline $1.620-1.600$ & $\begin{array}{l}\text { Deformação axial assimétrica do ânion carboxilato deionizado ou com ligação iônica com } \\
\text { metal; deformação axial de } \mathrm{C}=\mathrm{C} \text { de anel aromático }\end{array}$ & $\begin{array}{l}\text { Baes \& Bloom (1989) } \\
\text { Vinkler et al. (1976) }\end{array}$ \\
\hline $1.548-1.510$ & Amido secundário ou deformação axial de $\mathrm{C}=\mathrm{C}$ aromático & Hernandez et al. (1993) \\
\hline 1.452 & Deformação angular assimétrica de C-H em metil e metileno & Ricca et al. (1993) \\
\hline $1.420-1.400$ & Deformação axial simétrica do ânion carboxilato & Ricca et al. (1993) \\
\hline 1.380 & Deformação angular simétrica de C-H em metil e metileno & Ricca et al. (1993) \\
\hline $1.262-1.234$ & Deformação axial de C-OH em grupos carboxílicos ou fenólicos & $\begin{array}{l}\text { Baes \& Bloom (1989) } \\
\text { Ricca et al. (1993) }\end{array}$ \\
\hline 1.100 & Deformação angular de O-H em gibbsita & Russel (1987) \\
\hline $1.080-1.050$ & Deformação axial de C-O em polissacarídeos & Stevenson (1982) \\
\hline 1.030 & Deformação axial de Si-O em caulinita ou deformação angular de O-H em gibbsita & Russel (1987) \\
\hline 1.010 & Deformação angular de O-H em caulinita e gibbsita & Russel (1987) \\
\hline 910 & Deformação angular de O-H em caulinita & Russel (1987) \\
\hline $820-750$ & Deformação angular fora do plano de ligações C-H de anéis aromáticos & Baes \& Bloom (1989) \\
\hline 540 & Deformação angular de O-H em gibbsita ou caulinita & Russel, 1987 \\
\hline 470 & Deformação de Si-O em caulinita & Russel, 1987 \\
\hline
\end{tabular}


redução do teor de cinzas de 54 para $3 \%$ nos $\mathrm{AHs}$ extraídos do horizonte $\mathrm{A}$ do Latossolo e de 32 para 1,7\% nos AH s extraídos do horizonte A +E do Podzol. Piccolo (1988) encontrou redução no teor de cinzas em amostras de ácido húmico extraído em $\mathrm{NaOH}$ $0,1 \mathrm{~mol} \mathrm{~L}-1$, de 50 para $1 \%$, após purificação com $\mathrm{HF}+\mathrm{HCl}$, e redução significativa do pico em $1.050 \mathrm{~cm}^{-1}$ no espectro no infravermel ho, atribuída a ligações Si-O em minerais silicatados.

A coloração avermelhada da cinza dos ácidos húmi cos não purificados extraídos do horizonte $\mathrm{A}$ do
Latossolo revel ou a presença deferro como impureza, provavel mente em minerais de baixa cristalinidade, cujos sinais característicos estão fundidos em uma banda larga entre 700 e $400 \mathrm{~cm}^{-1}$ (Russel, 1987), encoberta pel os picos em 536 e $468 \mathrm{~cm}^{-1}$ da caulinita, não podendo ser claramente evidenciados (Figura 5).

Após a desmineralização do ácido húmico extraído do Latossolo, os picos relativos a ligações C-H al ifáticas em 2.918, 2.850, 1.452 e1.384 cm-1 eos picos em 1.544e $1.068 \mathrm{~cm}^{-1}$, relativos a polissacarídeos, tornaram-se mais evidentes (Figura 3). Em ambos

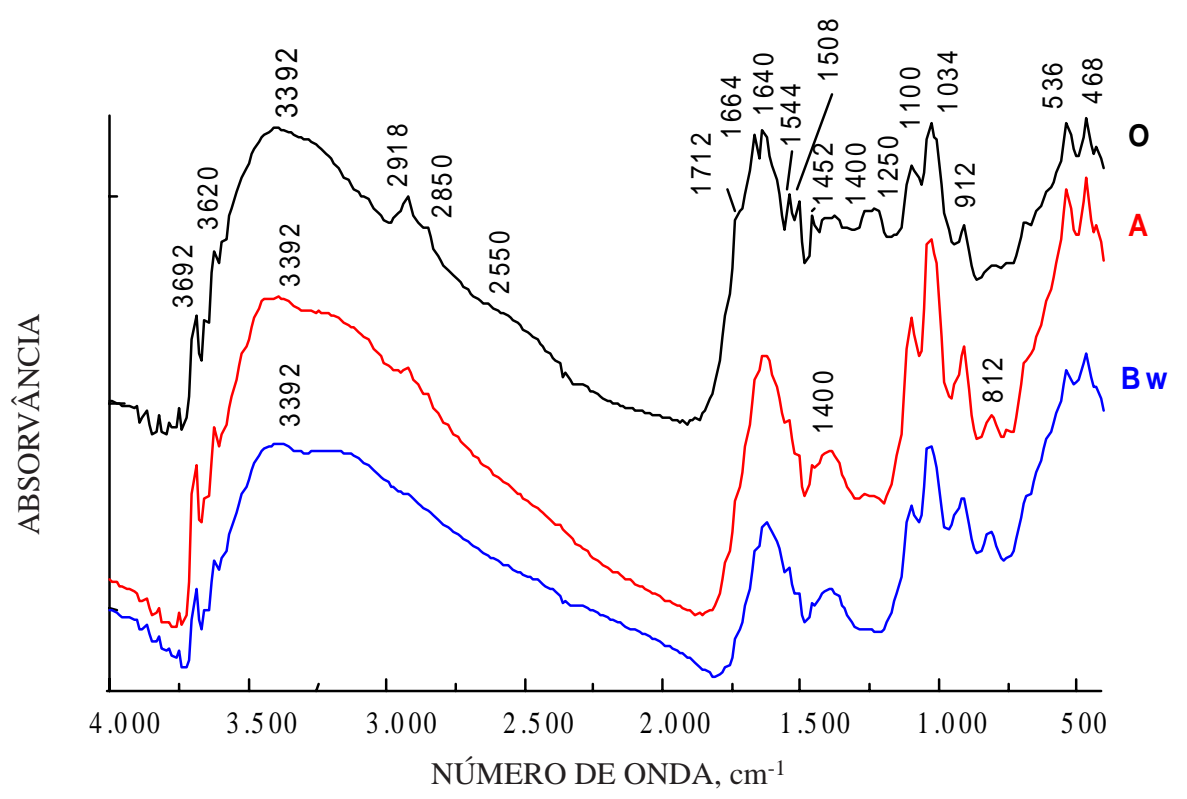

Figura 1. Espectros de absorvância no infravermelho dos ácidos húmicos não purificados, extraídos dos horizontes $\mathrm{O}, \mathrm{A}$ e $\mathrm{Bw}_{2}$ de um Latossolo Vermelho-Amarelo (perfil 12).

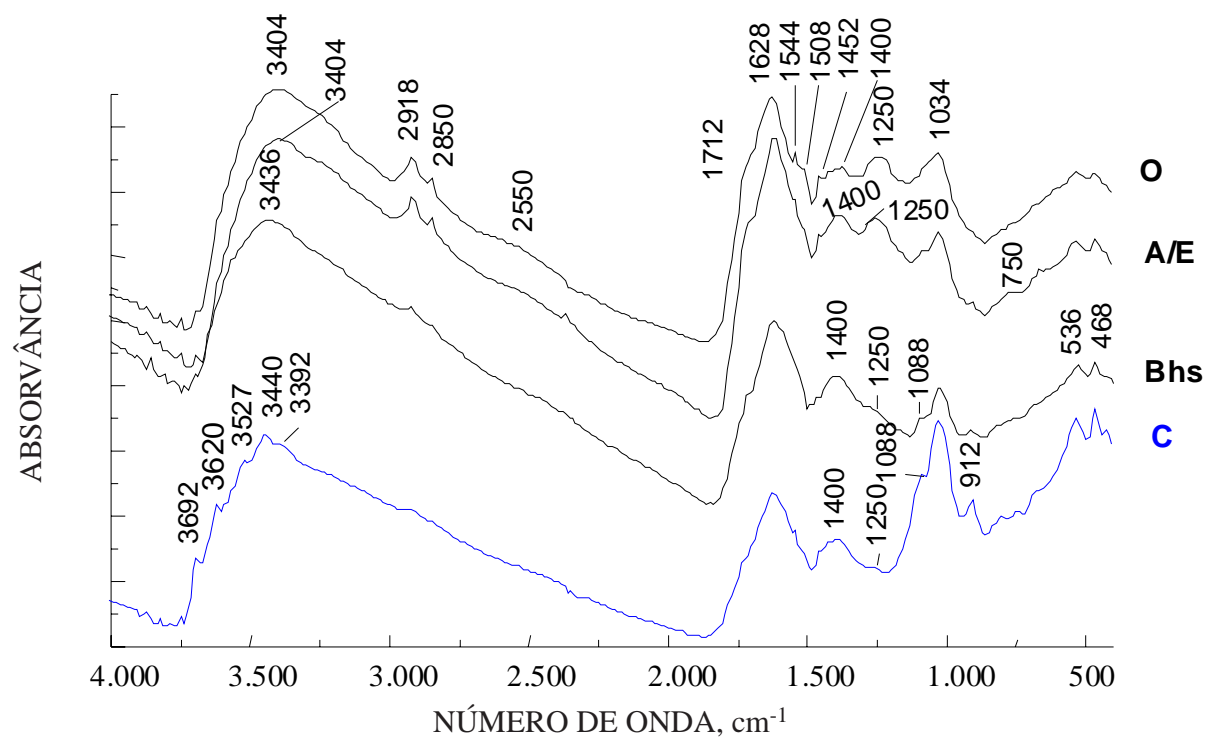

Figura 2. Espectros de absorvância no infravermelho dos ácidos húmicos não purificados, extraídos dos horizontes O, A + E, Bhs e C de um Podzol (perfil 3). 
os espectros de ácidos húmicos, extraídos do Latossolo e do Podzol, foram observados tanto a redução dos picos em 1.654-1.620 e $1.400 \mathrm{~cm}^{-1}$, relativos ao ânion carboxilato, como o aumento de intensidade dos picos em 2.550, 1.712 e $1.250 \mathrm{~cm}^{-1}$, relativos ao grupo carboxílico na sua forma hidrogenada, evidenciando o rompimento de ligações entre estes grupos e os minerais (Figuras 3 e 4). Segundo Piccolo (1988), o HF é capaz de romper ligações organometálicas, formando complexos solúveis com os minerais etornandolivres os grupos carboxílicos, permitindo sua determinação. Essefato concorda com o modelo em que grande parte das ligações entre ácidos húmicos e minerais de argila se dá pelos grupos carboxílicos (Hamblin \& Greenland, 1977).

Na comparação de espectros de ácidos húmicos não purificados, extraídos de diferentes horizontes de um mesmo perfil, algumas diferenças foram observadas (Figuras 1 e 2). No perfil do Latossolo (Figura 1), notou-se redução dos picos em 2.918, 2.850 e $1.452 \mathrm{~cm}^{-1}$, referentes a ligaçôes C-H em metil

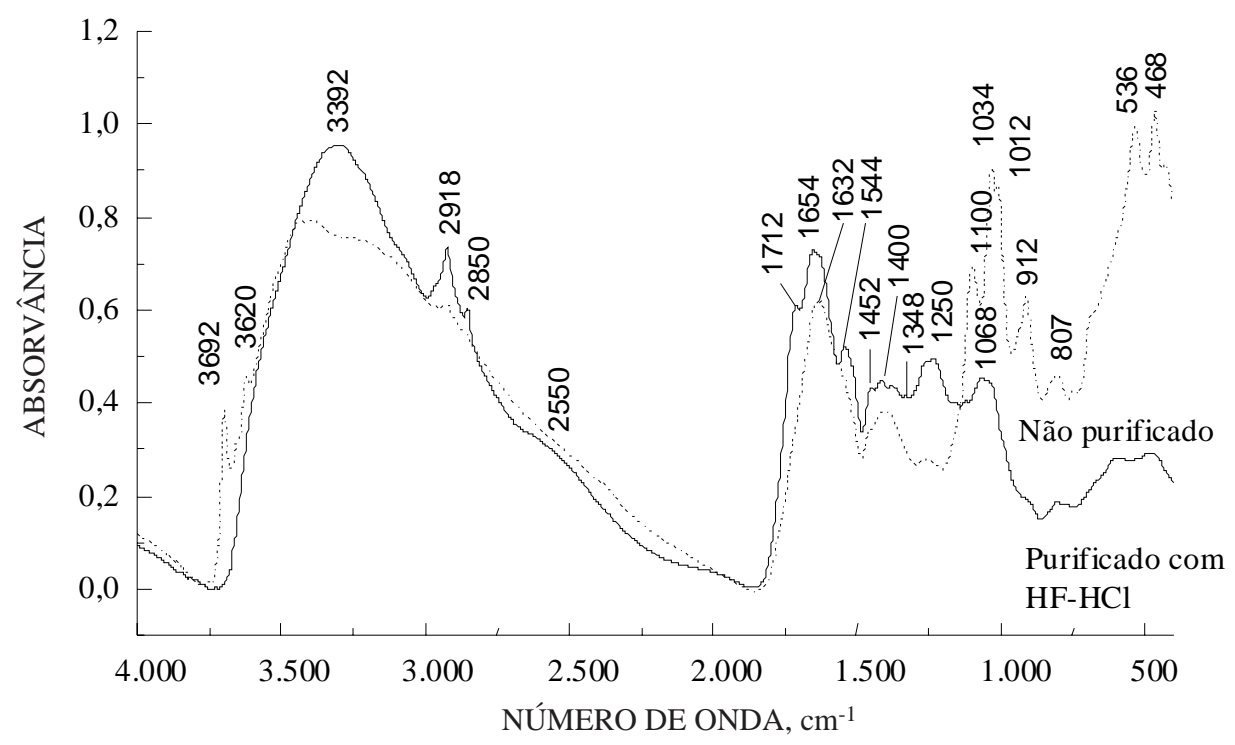

Figura 3. Espectros de absorvância no infravermelho dos ácidos húmicos purificados e não purificados, extraídos do horizonte A de um Latossolo Vermelho-Amarelo.

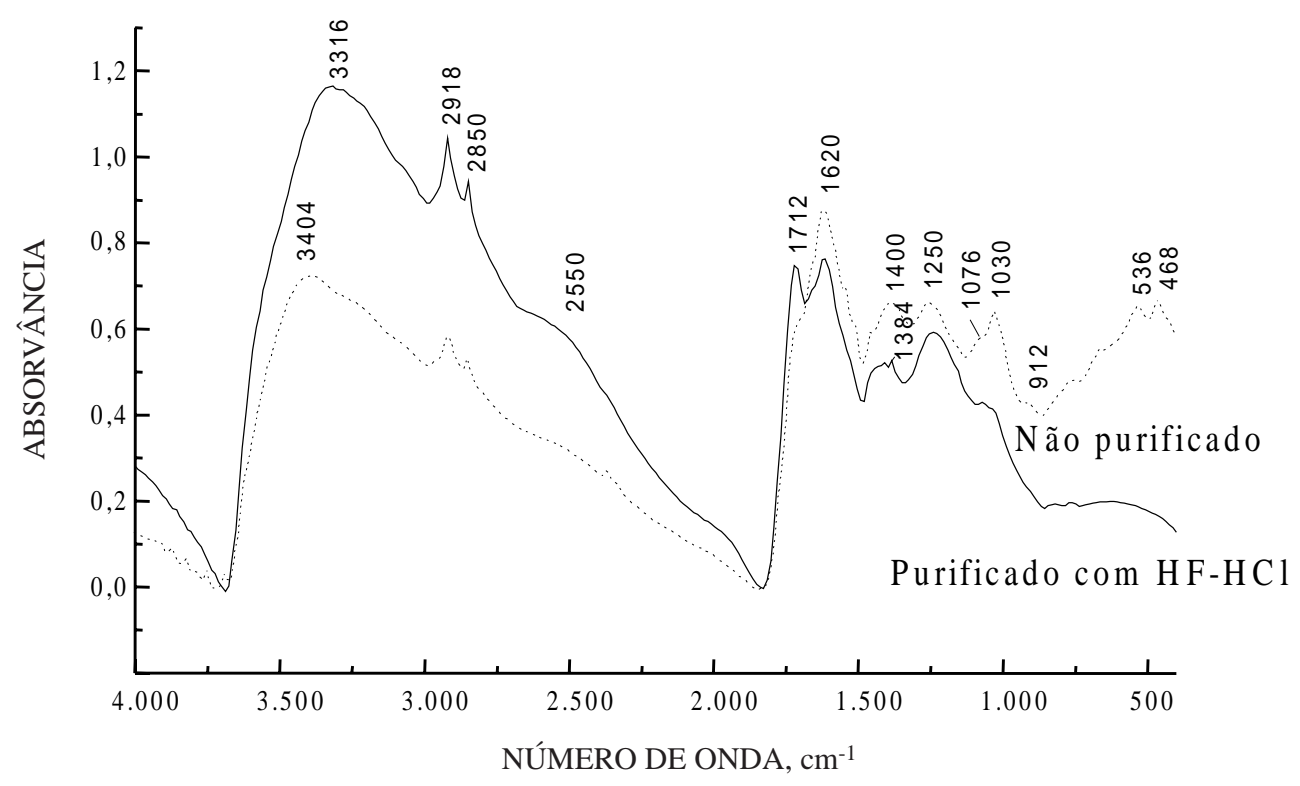

Figura 4. Espectros de absorvância no infravermelho dos ácidos húmicos purificados e não purificados, extraídos do horizonte Bhs de um Podzol. 
e metileno, dos horizontes superficiais, mais orgânicos, para os horizontes minerais. Stevenson (1982) relacionou estes picos a materiais mais alifáticos emais ricos em compostos não humificados, como carboidratos. Observou-se que a presença de minerais como impurezas nas amostras orgânicas foi menos expressiva que nas amostras minerais e, portanto, é possível que a redução dos picos referentes a estruturas orgânicas alifáticas entre as amostras seja, em parte, devido a um efeito de diluição causado pelo alto teor de cinzas das amostras dos horizontes minerais.

Entretanto, os picos em 1.544 e $1.508 \mathrm{~cm}^{-1}$ no espectro da camada orgânica indicaram a presença de pol issacarídeos, como anteriormenterelatado por Hernandez et al. (1993). Esses autores estudaram comparativamente os espectros de ácidos húmicos extraídos de composto de lodo de esgoto e de leonardito e atribuíram maior alifacidade ao primeiro, em virtude da presença de picos referentes a C-H alifáticos $\left(2.940,2.840\right.$ e $\left.1.470 \mathrm{~cm}^{-1}\right)$ eao amido (1.540-1.500 cm-1, 1.080-1.034 cm-1). Essa última banda, em 1.080-1.050 cm-1, referenteà deformação axial da ligação C-O em polissacarídeos (Stevenson, 1982), não pốde ser observada no espectro dos ácidos húmicos não purificados, por estar encoberta pelos picos referentes a impurezas minerais. A redução do caráter alifático em profundidade pôde ser também observada no Podzol (F igura 2).

Outra alteração observada com o aumento da profundidade foi o aumento da intensidade dos picos em 1.640-1.628 e $1.400 \mathrm{~cm}^{-1}$, referentes aos ânions carboxilatos, bem como a conseqüente redução da banda em 2.600-2.500 cm-1 e do pico em $1.712 \mathrm{~cm}^{-1}$, relativos ao grupo carboxílico em sua forma protonada (MacCarthy \& Rice, 1985). A coordenação das cargas de origem carboxílica com metais por ligações covalentes causa o deslocamento da freqüência de ressonância da deformação axial da ligação $C=0$ dos grupos carboxílicos, de $1.712 \mathrm{~cm}^{-1}$ para a faixa de $1.630-1.615 \mathrm{~cm}^{-1}$, de acordo com o metal envolvido e com a forma de coordenação (Vinkler et al., 1976).

A coordenação das cargas carboxílicas com argil ominerais, por meio de ligações coval entes com metais de superfícies cristalinas, ou com metais fazendo ponte entre a molécula orgânica e a superfície mineral, foi a causa das alterações observadas nos espectros. Essas formas de ligação são bastante comuns em solos tropicais, sendo considerados os principais mecanismos de ligação na formação de complexos organominerais (Greenland, 1970; Varadachari et al., 1997).

$\mathrm{Na}$ comparação entre os espectros de infravermelho de ácidos húmicos purificados, extraídos do horizonte espódico (Bhs) do Podzol edo horizonte superficial (A) do Latossolo, puderam ser constatadas algumas diferenças qualitativas que indicaram maior grau de humificação do primeiro (Figuras 3 e 4). Os picos em 1.544 e $1.068 \mathrm{~cm}^{-1}$, relativos a polissacarídeos, no espectro do ácido húmico extraído do Latossolo mostraram menor decomposição e menor grau de humificação deste. Segundo a classificação de Stevenson e Goh (Stevenson, 1982) para espectros de infravermel ho de substâncias húmicas, o espectro do ácido húmico extraído do Podzol enquadrou-se como do tipo I, definido como espectros típicos de ácidos húmicos

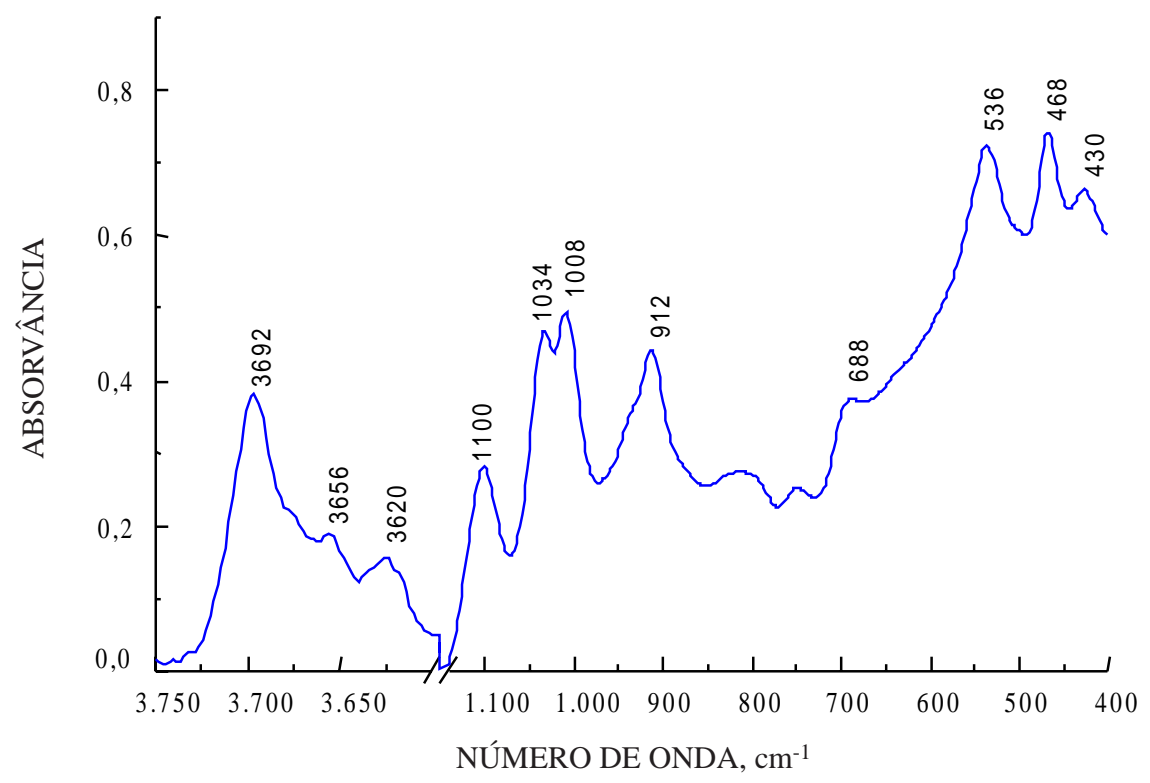

Figura 5. Espectro da di ferença de absorvância no infravermelho antes e depois da purificação dos ácidos húmicos, extraídos do horizonte A de um Latossolo Vermelho-Amarelo, evidenciando os picos referentes à caulinita. 
de solo, com bandas fortes em 3.400, 2.900, 1.720, 1.600 e $1.200 \mathrm{~cm}^{-1}$, tendo os picos em $1.720 \mathrm{e}$ $1.600 \mathrm{~cm}^{-1}$ apresentado aproximadamente a mesma intensidade. Pela mesma classificação, o espectro do ácido húmico extraído do Latossolo enquadrou-se como do tipo III, definido como espectros com as mesmas bandas observadas nos tipos I ell , além da presença de bandas próximas de 1.540 e 1.050 cm-1, relativas a carboidratos.

Os resultados da análise termodiferencial dos ácidos húmicos purificados, extraídos do Latossolo e do Podzol, corroboram a idéia de maior grau de humificação doácido húmico proveniente do Podzol , o qual apresentou maior resistência à termodegradação (Figura 6). 0 espectro termodiferencial desse ácido húmi co revelou um pico exotérmico com um máximo em $486^{\circ} \mathrm{C}$, enquanto o espectro termodiferencial do ácido húmico extraído do Latossol o apresentou um pico exotérmico com um máximo em $392^{\circ} \mathrm{C}$. Stevenson (1982) demonstrou a utilização de técnicas termodegradativas na avaliação da aromaticidade de substâncias húmicas, estando a maior resistência à termodegradação relacionada com a presença de núcleos aromáticos mais condensados. Entretanto, em virtude da escassez de trabalhos de análise termodiferencial com substâncias húmicas em ambientes tropicais, interpretações quantitativas devem ser evitadas e a utilização desta técnica visa auxiliar a interpretação de dados obtidos em outras análises espectroscópicas.

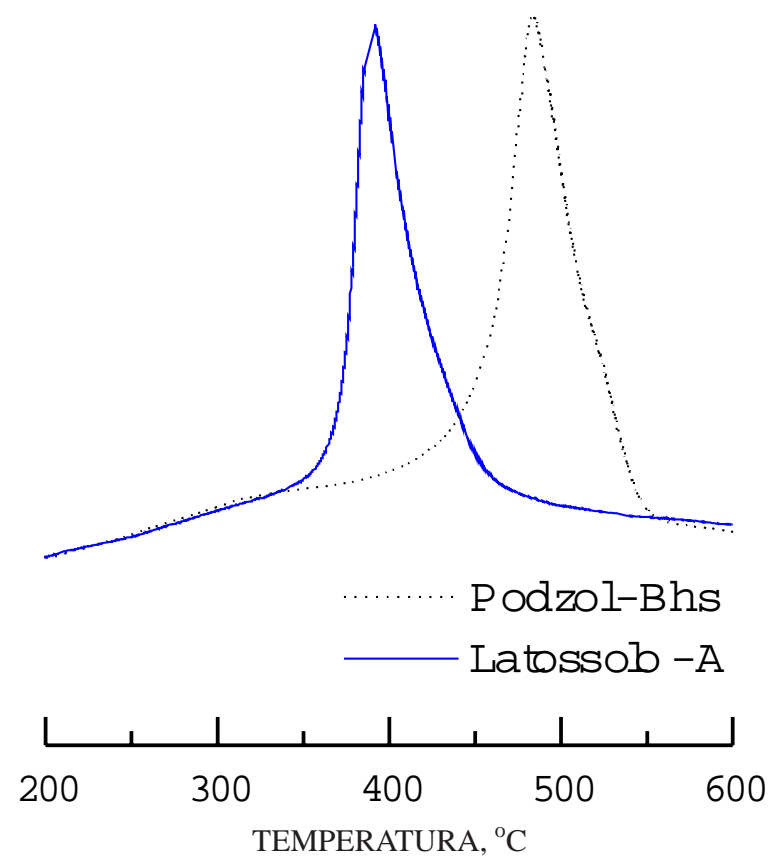

Figura 6. Espectro de análise termodiferencial de ácidos húmicos purificados, extraídos do horizonte A de um Latossolo Vermelho-Amarelo e do horizonte Bhs de um Podzol.

\section{CONCLUSÕES}

1. A espectroscopia no infravermel ho e a análise termodiferencial foram importantes ferramentas na identificação de difer enças qual itativas entreácidos húmicos provenientes de diferentes pedoambientes, notadamente por apresentarem um custo relativamente baixo, quando comparadas a outras técnicas espectroscópicas.

2. A purificação dos ácidos húmicos com $\mathrm{HF}-\mathrm{HCl}$ foi necessária para eliminar impurezas minerais e observar alguns picos referentes a estruturas orgânicas, encobertos pelo sinal das impurezas. A não-eliminação de cinzas pode dificultar ou até impedir a interpretação dos espectros.

3. Verificou-se que grupos carboxílicos estavam envol vidos nos processos de ligação entre os ácidos húmicos e a matriz mineral, embora a técnica utilizada não seja suficiente para confirmar tal afirmativa, sendo necessário o emprego associado de outras análises espectroscópicas.

4. Um estudo mais amplo, envolvendo maior numero de classes de sol os em ambientes tropicais, é necessário para se estabel ecerem as correlações entre a feição dos espectros eo pedoambiente de onde foi extraído o ácido húmico.

\section{LITE RATURA CITADA}

BAES, A.U. \& BLOOM, P.R. Diffuse reflectance and transmition Fourier transform infrared (DRIFT) spectroscopy of humic and fulvic acids. Soil Sci. Soc. Am. J ., 53:695-700, 1989.

BENITES, V.M. Caracterização química e espectroscópica da matéria orgânica e suas relações com a gênese de sol os da Serra do Brigadeiro, Zona da Mata mineira. Viçosa, Universidade Federal de Viçosa, 1998. 125p. (Tese de Mestrado)

GREENLAND, D.J . I nteractions between humic and fulvic acids and clays. Soil Sci., 111:34-41, 1970.

HAMBLIN, A.P. \& GREENLAND, D.J. Effect of organic constituents and complexed metal ions on aggregate stability of some East Anglian soils. J . Soil Sci., 28:410-416, 1977.

HERNANDEZ, T.; MORENO, J.I. \& COSTA, F. Infrared spectroscopic characterization of sewagesludge humic acids. Evidence of sludge organic matter-metal interactions. Agrochimica, 37:12-17, 1993.

MacCARTHY, P.E. \& RICE, J .A. Spectroscopic methods (other than NMR) for determining functionality in humic substances. In: AIKEN G.R.; McKNIGHT D.M.; WERSHAW, R.L. \& McCARTHY P., eds. Humic substances in soil, sediment and water: geochemistry, isolation and characterization. New York, J ohn Wiley \& Sons, 1985. p.527560.

PICCOLO, A. Characterization of soil humic extracts obtained by some organic and inorganic solvents and purified by HCl-HF treatment. Soil Sci., 146:418-426, 1988. 
RICCA, G.; FEDERICO, L.; ASTORI, C. \& GALLO, R. Structural investigations of humic acid from leonardite by spectroscopic methods and thermal analysis. Geoderma, 57:263-274, 1993.

RUSSEL, J.D. infrared methods In: WILSON, M.J ., ed. A handbook of determinative methods in clay mineralogy. London, Blackie \& Sons, 1987. p.133-173.

SCHNITZER, M. Chemical, spectroscopic, and thermal methods for the classification and characterization of humic substances. In: INTERNATIONAL MEETING ON HUMIC SUBSTANCES, 1972, Wageningen. Proceedings. Wageningen, Pudoc, 1972. p.293-310.
SCHNITZER, M. Organic matter caracterization. In: PAGE, A.L.; MILLER, R.H. \& KEENEY, D.R., eds. Methods of soil analysis. Part 2. Madison, SSSA, 1982. p.581-594. (Agronomy, 9)

STEVENSON, F.J . Humus chemistry. New York, J ohn Wiley \& Sons, 1982. 443p.

VARADACHARI, C.; CHATTOPADHYAY, T.E. \& GHOSH, K. Complexation of humic substances with oxides of iron and aluminum. Soil Sci., 162:28-34, 1997.

VINKLER, P.; LAKATOS, B. \& MEISEL , J . I nfrared spectroscopic investigations of humic substances and their metal complexes. Geoderma, 15:231-242, 1976. 